\title{
ENSINO DE FILOSOFIA FACE AO PRECONCEITO E EXCLUSÃO DA MULHER NO CORPUS FILOSÓFICO
}

\author{
PHILOSOPHY'S TEACHING IN THE FACE OF PREJUDICE AND \\ EXCLUSION AND WOMEN IN THE PHILOSOPHICAL CORPUS
}

\author{
Rosa Alfredo Mechiço ${ }^{1}$
}

Recebido em: 07/2020

Aprovado em: 08/2020

\begin{abstract}
Resumo: A história do pensamento filosófico ocidental é masculinizada, o que torna claro que a filosofia tem, ou pode ter, um caráter ideológico (ideológico no sentido de encobrimento de relações de poder ilegítimas), mas pode também possuir um potencial emancipatório que reside em sua força crítica. Outrora rejeitada e até marginalizada, na actualidade nota-se um esforço aguerrido por parte da mulher no sentido de libertar-se das amarras que lhe foram imposta pela educação moral tradicional e pela religião. A mulher sente que é chegado o momento de livrar-se do cativeiro, sair da caverna, isto é, do confinamento, do esquecimento e silenciamento e ousar pensar por si própria, encarnando a possibilidade de recuperação de suas experiências, vivências, ideias e conhecimento. Este processo passa pela constituição de um corpus filosófico não-sexista, identificação das filósofas, inclusão de produções intelectuais femininas em obras e nos curricula que possibilitem a existência de debates internos que mostram a força do pensamento feminino no âmbito da filosofia, um pensamento que já gera teorias próprias que debatem entre si.
\end{abstract}

Palavras-chaves: Desafios; Exclusão; Filosofia; Mulher; Preconceito.

\begin{abstract}
The history of Western philosophical thought is masculinized, which makes it clear that philosophy has or may have an ideological character (ideological in the sense of concealing illegitimate power relations) but may also possess an emancipatory potential that lies in its critical force. Once rejected and even marginalized today, one notices a fierce effort by women's intellect to free themselves from the bonds imposed on them by traditional moral education and religion. The woman feels that the time has come to free herself from captivity, to get out of the cave, that is to say, from confinement, from forgetfulness and silencing and to dare to think for herself, embodying the possibility of recovering her experiences, ideas and knowledge. This process involves the constitution of a non-sexist philosophical corpus, the identification of philosophers, the inclusion of feminine intellectual productions in works and curricula that allow the existence of internal debates that show the strength of feminine thought in the scope of philosophy, a thought that already generates its own theories that debate among itself.
\end{abstract}

Keywords: Challenges; Exclusion; Philosophy; Woman; Prejudice.

\footnotetext{
${ }^{1}$ Universidade Pedagógica de Maputo, Moçambique, rosamechico@gmail.com
} 


\section{Introdução}

O presente ensaio é uma reflexão sobre o ensino de filosofia face ao preconceito e exclusão da mulher no corpus filosófico.

A reflexão traz, à tona, aspectos que se encontram referenciados no pensamento e/ou reflexões de alguns autores em relação ao tema em discussão, em razão disso, fundamenta-se, essencialmente, em dados documentados, isto é, bibliográficos. Por um lado, a mesma, pretende demonstrar que o campo da filosofia, isto é, do amor a sabedoria, desde os primórdios foi sexista e, por via disso, evidenciar a necessidade de encetar-se uma luta firme e contínua contra o preconceito existente em relação as mulheres que actuam na filosofia, seja como pesquisadoras, formadas de opinião e nas salas de aulas. Por outro lado, a reflexão guia-se pelo intuito de demonstrar a necessidade, pertinência e urgência de recuperar-se a memória das mulheres filósofas, isto é, suas produções intelectuais nas salas de aulas em particular e na história da filosofia em geral. Pretende, ainda, ser um contributo no sentido de as mulheres serem, cada vez mais, mais presentes nas reflexões de âmbito filosófico, estimulando-as a produzir conhecimento e/ou saberes a partir de suas próprias vivências, anseios e realizações. De modo geral, o leit motiv da presente reflexão é incentivar o respeito, reconhecimento e valorização da mulher filósofa, permitindo que ela pense e se assuma como tal, isto é, identifique-se, situe-se e construa-se como mulher filósofa e mulher na filosofia e, por conseguinte, actue neste campo de saber livre de toda a espécie de preconceitos.

No que concerne à metodologia, a reflexão em curso adopta a desconstrução e construção, acompanhada pela interpretação reflexiva e crítica.

Em termos de estrutura seguir-se-á a seguinte: após a introdução é apresentada a história da filosofia como gênese do preconceito e exclusão da mulher na filosofia. De seguida apontase a educação moral tradicional e a religião como factores decisivos e salutares na exclusão da mulher na vida social, cultural, económica, política, científica e académica. Estes dois primeiros pontos são tomados como aspectos de fundo, ou seja, o centro nevrálgico e gravitacional, à medida que alimentam e retroalimentam a discussão que se estabelece em torno da reflexão em causa. Consecutivamente, são trazidas algumas condições julgadas como preliminares que contribuíram para ascensão gradual da mulher à educação e por consequência à filosofia. De seguida é desenvolvida a questão ligada a ausência de literatura filosófica feminina na história da filosofia e consequentemente no ensino de filosofia. Posto isso, sucessivamente abre-se um espaço onde são retractados e vincados alguns elementos apontados como desafios no ensino 
de filosofia que se pretende livre do preconceito e da exclusão da mulher. Concomitantemente esses desafios são considerados crivos na edificação e identificação de uma filosofia não mais sexista, preconceituosa e excludente. Por fim, são tecidas as considerações finais e apresentada a bibliografia usada como suporte teórico e científico da pesquisa.

\section{A história da filosofia como gênese do preconceito e exclusão da mulher na filosofia}

(...) em geral os homens e as mulheres têm, uns para com os outros, um soberano desprezo e combatem à porfia quem trata pior o outro; quando pelo contrário, deveriam viver felizes, se ambos os sexos se resolvessem a tomar um pelo outro os sentimentos de estima que se devem reciprocamente (FLORESTA, 1989, p. 90 Apud ROSA, 2012, p. 79).

A história oficial da filosofia configurada pelo corpus consagrado é testemunha do facto de a mãe da Sapiência (a filosofia) desde o início da sua existência e/ou história ter desabrigado e desamparado as suas filhas, e por consequência a história das mulheres filósofas anuncia-se como uma história à parte, não tão-somente da história da filosofia mas também da história universal.

Embora a filosofia se apresente como um pensamento sem gênero (gênero enquanto conceito e categoria que nas ciências sociais é usada para a elaboração, estruturação e análise sócio histórica das identidades masculina-homem e feminina-mulher), desde cedo escolheu um género, no caso o masculino. $\mathrm{O}$ homem colocou-se no centro e colocou a mulher na periferia. Esta atitude contribui para que na filosofia a mulher seja colocada à margem, o que torna claro que "as mulheres não pertencem inicialmente a essa história de acesso ao saber, que lhes fora negado, impedindo, consequentemente, a própria possibilidade de humanização” (MENEZES, 2002, p. 13).

Ora, a releitura do contexto histórico social revela que desde os primórdios a filosofia apresenta-se como um campo do saber masculinizado e sexista. Outrossim, a releitura do contexto confirma que o acesso à porta frontal do "amor a sabedoria" por parte das mulheres fecha-se, porquanto lhes é explicitamente negado.

Há uma estrutura de domínio, cúmplice de um certo sentimento de posse, superioridade e desprezo, subjacente na mente e nas atitudes masculinas em relação à mulher. Essa estrutura é responsável pela incapacidade de valorização da singularidade do sujeito humano, quer seja mulher ou se trata do próprio homem.

A bem dizer, a hierarquização dos sexos, que culmina na subalternização da mulher (do 
seu papel e seu status), é algo existente na História da Filosofia e fortemente defendida na Filosofia da Educação. Grandes filósofos como Aristóteles, Hegel, Rousseau, Kant entre outros, em seu pensamento filosófico para sustentar a inferioridade das mulheres afirmaram realidades incrivelmente pejorativas sobre elas, tomando-as como o "segundo sexo".

Eis, portando, em traços gerais, o que se pode dizer acerca do preconceito da mulher na Filosofia: "Na Grécia, os mitos contavam que, devido à curiosidade própria de seu sexo, Pandora tinha aberto a caixa de todos os males do mundo e, em consequência, as mulheres eram responsáveis por haver desencadeado todo tipo de desgraça" (PULEO, 2004, p. 1).

Rousseau (1712-1778) reconhecido e apreciado como o maior pedagogo da autonomia, ao defender que a criança deve ser deixada livre para desenvolver sua personalidade sem nenhum tipo de interferência, no Emílio (1762), Vol. II, livro V, sustenta que toda a educação das mulheres deve estar limitada a seus deveres para com os homens, "agrada-lhes, sê-lhes úteis, fazer-se amar e honrar por eles" (...) "aconselhar, consolar, fazer-lhes a vida agradável e doce". Criar-lhes os filhos e cuidar-lhes quando idosos. Assim, ao enaltecer as virtudes de Sofia e patenteá-la como protótipo de menina que assimilando as virtudes se tornaria uma excelente esposa e mãe exemplar, deixou claro a função coadjuvante da mulher na ordem e na manutenção da família.

No entanto, bem analisado, a liberdade outorgada à criança diz respeito tão-somente ao Emílio, representante do gênero masculino, não abrangendo a Sofia representante do gênero feminino. Para a Sofia o preceito é diferente. Em relação à Sofia assevera-se que não se deve deixá-la desenvolver-se livremente, mas, à dura penas, deve aprender a submissão, aprender a viver para outros, a fingir e a manter as aparências.

Pestalozzi (1746-1827), filósofo da educação, no Leonardo y Gertrudes (1981) enfatizou os deveres e/ou as obrigações sociais e a conduta de mulher, enquanto aquela que exclusivamente lhe cabe o papel virtuoso de futura esposa e mãe.

Kant (1724-1804) um dos grandes pensadores da autonomia, à semelhança de Rousseau, reitera que às mulheres cabe-lhes o singelo papel de civilizadoras do homem. Sua nobre tarefa é polir a descortês forma de ser do "macho". Todavia, assegura que, infelizmente, nenhuma mulher é capaz de um julgamento moral, porquanto é a sua doçura e o encanto que lhe permite civilizar, o que de forma alguma garante-lhe a possibilidade de vir a alcançar a autonomia. Portanto, cabe as mulheres o dever de aprender as normas e docilmente deixar-se guiar por elas.

Em analogia com o pensamento de Rousseau, a célebre expressão kantiana “ouse pensar" que é uma ordem para atrever-se a saber, e por consequência permitir-se guiar pelo seu 
próprio entendimento, num paralelismo com o que acontece com a liberdade de Rousseau, em Kant nota-se claramente que o atrevimento ao pensar por si próprio não alcança as mulheres.

Com efeito, o que se pode observar é uma incontestável contradição diante de grandes afirmações vindas de dois expoentes da Filosofia, Rosseau e Kant. Enquanto ambos, categoricamente, por um lado, afirmam a igualdade de todos os homens, portanto seres humanos (homens e mulheres) e o seu direito à autonomia, por outro lado, também de modo categórico, afirmam que as mulheres devem estar submetidas e tuteladas pelos homens.

Das considerações acima assume-se uma limitação manifesta na ausência de coerência no âmago de um pensamento que se pretende ser universal, isto é, válido para todos os seres humanos. Há inexistência de congruência no interior de uma concepção na qual é forçoso haver uma certa concordância, o que leva a uma contradição entre os grandes princípios proclamados e sua não aplicação às mulheres.

Ainda nesta trajectória de desvendamento do preconceito e exclusão da mulher, vale lembrar

o caso da exclusão das mulheres da cidadania no momento da instauração das democracias modernas: célebres médicos-filósofos como Cabanis fundamentaram o não-reconhecimento dos direitos políticos como o voto, com sua teoria da debilidade cerebral da mulher e com os preceitos da Higiene, que recomendavam sua dedicação integral à maternidade (FRAISSE, 1989) (PULEO, 2004, p. 2).

Daqui, segue-se que tudo o que se disse até então denota que há um profundo enraizamento histórico filosófico do preconceito e descriminação contra a mulher no geral, que de forma exposta passou para mulher filósofa em particular. E, de certo modo, a filosofia moderna apresenta-se como aquela que de forma clássica engendrou a divisão entre a esfera pública (do pensamento, do saber, da política, do trabalho assalariado, do produtor, etc.), tida como aquela que pertence unicamente ao homem e a esfera doméstica (de mulher virtuosa e zelosa, boa esposa e mãe) a que por excelência cabe à mulher. Todavia, o que sempre observouse e de forma alguma se difere com o que acontece no cotidiano é facto de, no âmbito do público o homem ser considerado superior, mas secretamente apoiar-se no mundo doméstico, o mundo da mulher, o qual ele tem marginalizado. 


\section{A educação moral tradicional e a religião como factores decisivos e salutares na exclusão da mulher}

Desde já há toda a conveniência, no que toca a educação da mulher, em ressaltar que poucas mulheres tiveram, têm, ou ainda têm tido o privilégio da possibilidade de acesso a educação e/ou instrução escolar. As meninas, a partir da tenra idade recebem uma educação moral tradicional e ensinamentos religiosos, de digna submissão, educando-as para alcançar a espectativa de uma sociedade de modelo patriarcal e plena dependência do homem. É decerto natural a tendência de uma educação reservada para a mulher sempre voltada para a edificação da família (magnífica e notável esposa), função maternal (perfeita e admirável mãe), trabalho doméstico, manutenção da ordem no lar, na vida familiar e social, responsabilidade pelos demais, ou seja, cuidado e zelo pelos outros, em suma viver para os outros (ROSA, 2012, pp. 32-33).

Os factos colocam em evidência que dos diversos preceitos vigorosamente disseminados pela educação moral tradicional e pela religião destaca-se o seguinte:

A menina deveria ser boa, para se tornar uma boa mulher e conseguir um bom matrimónio, atingindo as espectativas como: ter família feliz, cuidar bem de seus filhos, seguir o exemplo de mulher virtuosa, despertando o orgulho do esposo. Deveria seguir o modelo patriarcal de comportamento e por isso se mantinha oprimida e dependente de outras pessoas - seus filhos e esposo (ROSA, 2012, p. 30).

Ademais,

na valorização da instituição do casamento considerado pilar da vida privada e estrutura da família - à mulher caberia um lugar de destaque, fosse esposa, mãe, filha, (...) deixando-a para sempre dependente materialmente do homem, que reiterava a eterna delicadeza, a fragilidade e incapacidade para grandes decisões. Á mulher, nessa sociedade positiva, cabia ser apenas a companheira do homem: sua sombra, sem individualidade própria (Ibid., p. $37)$.

Neste enfoque a religião é a instituição que de forma agressiva, mas carismática, também apresentou um dos mais importantes, senão o maior, discurso de legitimação da superioridade do homem em relação à mulher. Ela é sem dúvida o mais antigo modelo de legitimação de poderes, a partir da divisão social.

Convém esclarecer que, de modo geral, em virtude da importância do papel da religião 
e com base também nas suas peculiaridades,

as grandes religiões têm justificado ao longo dos tempos os âmbitos e condutas próprios de cada sexo. Na tradição judaico-cristã, o relato da expulsão do Paraíso tem essa função. Eva é a Pandora judaico-cristã porque, por sua culpa, fomos desterrados do Paraíso. Assim, a exaltação da humildade e obediência da Virgem Maria em um momento de auge das sufragistas parece ter tido como objetivo limitar a força desse movimento reivindicativo (Wagner, 1991) (PULEO, 2004, p. 1).

Aparte isso, no interior da igreja houve religiosos, posteriormente canonizados e aclamados como grandes santos, que dedicaram-se à escrita contra as mulheres, sustentando que por culpa delas entrou e subsiste o pecado no mundo e que "graças" à sua luxúria sem freios e/ou domínio continuamente incitaram os homens a pecar. Religiosos que lembravam, de forma dilacerante, a figura de Eva como causadora da expulsão do paraíso prometido ao majestoso Adão, e apontavam a impureza da mulher explícita no sangue do seu ciclo menstrual, etc.

No entanto, há que salientar que, na época moderna com o despontar de uma sociedade secular o discurso religioso visceralmente irradiado na Idade Média transmuta-se para o âmbito das ciências e da filosofia das luzes.

Outrossim, é importante ter em linha de conta o facto de que, ao mesmo tempo que a educação moral tradicional de modelo patriarcal e a religião explicitamente pareciam louvar e/ou engradecer os atributos da mulher, isto é, seus dotes, qualidades, habilidades, competências, virtudes, etc., como esposa e mãe, colocando-a em um patamar social fictício, na realidade, implicitamente enalteciam e reafirmavam a sua posição de inferioridade e o seu lugar de subalterna.

Conforme se pode depreender, tanto na educação moral tradicional quanto na religião, reiteradamente, à mulher foi-lhe reservado os espaços de clausura (lar ou convento). "O lar é, portanto, para ela o quinhão que lhe cabe na terra, a expressão de seu valor social, de sua mais íntima verdade" (BEAUVOIR, 1980, p. 197) e nada de vida pública. De qualquer modo, ambos tinham como foco assegurar na mulher a obediência subordinada às ordens masculinas e a renúncia à si própria, isto é, renúncia ao seu ser, à sua identidade, à sua vontade e seus desejos, tendo, assim, uma vida regulada e controlada, por forma a tão-somente servir os outros e, desse modo, contribuir para a ordem social, a partir dos papeis sociais tradicionalmente e severamente atribuídos e impostos ao sexo feminino; ser melhor esposa e melhor mãe (atender ao marido e aos filhos) e melhor dona de casa (cuidar zelosamente dos afazeres domésticos - deveres e obrigações do lar). 
Ora, no esforço para manter a mulher na suposta cultura dos bons hábitos e virtudes inerentes às suas futuras funções de esposa e mãe exemplar, a estratégia usada pela educação moral tradicional e pela religião para lograr seus intentos foi "delimitar o papel das mulheres, normatizar seus corpos e almas, esvaziá-las de qualquer saber ou poder ameaçador, domesticálas dentro da família” (PRIORI, 1995, p. 17).

É claro, portanto, que por bastante tempo predominou a cultura habitual de descriminação e exclusão, fruto da educação da moral tradicional e da religião, baseada na ideia segundo a qual a mulher, sendo o esteio moral da família, deve ser confinada ao espaço familiar, resignando-se a todo o tipo de aspiração de realização pessoal e dedicar-se unicamente ao lar como esposa virtuosa e mãe devotada. E infelizmente, até então é notório o facto de que "a mulher vive presa à imagem que a sociedade masculina lhe impõe” (PAZ, 1984, p. 178).

$\mathrm{Na}$ verdade, no seguimento do que acabou-se de referir, parece óbvio que ao especificar o que é característico de cada sexo e determinar os espaços, direitos, deveres, actividades e conduta que cabia a cada sexo a educação moral tradicional e a religião estabeleceram e legitimaram o discurso sexual e simultaneamente justificaram a hierarquização do homem e da mulher, que culminou com a desigualdade de gênero e distribuição de papéis e do status do homem e da mulher na sociedade.

Com base neste entendimento, é oportuno elucidar que o papel e o status são dois elementos constituintes do sistema do gênero. Por seu lado, o papel refere-se à divisão do trabalho a partir do sexo, porém com a distinção de dois campos de acção, nomeadamente a esfera pública, considerada como a da razão, da igualdade diante da lei, e a esfera doméstica, que compreende as necessidades corporais. Estas, por sua vez, envolvem a imprescindibilidade do alimento, descanso, e afecto, que pode culminar ou não em relações sexuais, do apoio emocional, tarefas essas sempre contentadas pela mulher, a partir do cuidado feminino. Por seu turno, o status remete à hierarquia entre os dois sexos, ou se preferimos gêneros. Constitui o marco, por excelência, da desigualdade valorativa dos papéis exercidos na esfera pública e doméstica, que paradoxalmente gera a dificuldade de reconhecimento social, profissional, intelectual, e artístico, livres do preconceito.

\section{Passos da ascensão gradual da mulher à educação e por consequência à filosofia}

Acredito que a ciência não é masculina e nem feminina, mesmo que se tenha na história tentado construí-la a partir de concepções e investigações do sexo masculino, e desse modo, negando, ocultando, aniquilado, jogando fora, 
queimando ou renomeando investigações feitas por mulheres (CUNHA, 1998, p.40 Apud ROSA, 2006, p. 29).

Num certo sentido, pode-se afirmar então que não há dúvidas que, com o passar do tempo a clara e incisiva máxima de Kant “ouse pensar”, isto é, atreva-se a pensar por si mesmo, aprenda a pensar com liberdade e autonomia, arisque a guiar-se pela própria razão, sem a intromissão e/ou interferência de conselheiros, tutores, autoridade religiosa, hierarquia política etc., que limitam o pensamento, a liberdade e autonomia, extraordinariamente começou a ressoar no interior das mulheres, animando-lhes a iniciar mudanças nas estruturas sociais, tendo como base o direito natural que declarava a igualdade de todos os homens, isto é, dos seres humanos.

A esse respeito, considera-se como o primeiro momento histórico de luta pela emancipação o "memorial dos agravos".

Com o conceito de "memorial de agravos", a filósofa Célia Amorós se refere àqueles escritos anteriores ao século XVII e XVIII, (...). Trata-se de textos que se queixam da injustiça que sofrem as mulheres e reivindicam a excelência do sexo feminino. São obras que normalmente se inscrevem dentro da chamada "querelle des femmes", uma polêmica que durou vários séculos (PULEO, 2004, p. 9).

O considerado segundo momento é o dos escritos abertamente feministas onde as mulheres "reivindicam a igualdade no aceso a todas as atividades próprias da humanidade, o aceso (...) a todos os papéis e funções sociais sem discriminação” (Ibid., p. 10).

$\mathrm{Na}$ realidade, dentre os diversos pensadores e eventos que tiveram um papel preponderante nesta batalha emancipatória destacam-se os seguintes:

Poulain de La Barre, que seguindo os passos do seu mestre René Descartes, ao lutar contra os preconceitos a partir do uso exclusivo da razão, em sua obra De l'égalité des sexes traz a tona aquilo que segundo o seu modo de pensar constitui o preconceito mais profundo e antigo, o preconceito da inferioridade das mulheres. Assevera que se a humanidade, através da razão, for capaz de superar este preconceito grave então estará em condições de superar todos os outros, dado que este é o mais profundo (PULEO, 2004, p. 11).

Madame Lambert, moralista do Séc. XVIII, em muitas das suas obras sublinhou a ideia segundo a qual a moral não teme sexo. Portanto, tanto o homem quanto a mulher deviam submeter-se às regras sem nenhuma distinção. Ela foi contra o "duplo código", e condenou a moral sexual que permitia certo tipo de conduta aos homens e a mesma conduta não era aceite 
nas mulheres. Foi contundente ao afirmar que a moral deve reger da mesma maneira os seres humanos sem excepção de sexo. Concomitantemente, declarou que a honestidade, a justiça, o respeito, a dignidade etc., não devem variar segundo os sexos (Ibid., p. 11).

No século XIX voltará a se ouvir o mesmo protesto contra o duplo código. Quando as sufragistas pediam o voto, as vezes o faziam com cartazes que diziam: "Votos para as mulheres e castidade para os homens", denunciando costumes e idéias morais permissivas para com a promiscuidade sexual dos homens em uma sociedade que castigava sem misericórdia qualquer afastamento feminino do imperativo do mais estrito pudor (Id.).

Jean le Rond d'Alembert (1717-1783), filósofo feminista, matemático, físico e codirector da Encyclopédie, em uma carta dirigida a Rousseau para além de contestar parte de suas ideias refentes ao Emílio, servindo-se da oportunidade afirma que recusar a educação às mulheres equivale a retirar as armas a um povo vencido na guerra, de modo igual é impedir que oportunamente elas realizem obras de génio. Afiança que é errado e inadmissível confundir a suposta fragilidade do corpo da mulher com ser de natureza inferior (Ibid., p. 12).

Olympe de Gouges (1748-1793) é uma figura proeminente no período da Revolução Francesa, que conciliava a teoria com a acção política. Gouges é pensadora e dramaturga paradigmática que, infelizmente, em 1793 foi guilhotinada devido as suas ideias deveras avançadas. Dentre os seus feitos corajosos destaca-se a defesa pela libertação dos escravos negros em sua obra de teatro L' esclavage des noirs, a escrita sobre os direitos da mulher e a

Declaração dos Direitos da Mulher e da Cidadã, concebida como resposta e complemento à famosa Declaração dos Direitos do Homem e do Cidadão, que não incluía as mulheres. Em sua Declaração, afirmava que "a mulher que tem o direito de subir ao cadafalso deve ter também o direito de subir à tribuna" (PULEO, 2004, p. 12).

As mulheres eruditas do Séc. XVII e criadoras da opinião pública da época, que ao abrir salões literários e filosóficos inauguraram e presidiram espaços democráticos. Espaços nos quais, apesar da separação social entre nobres e plebeus, própria do sistema feudal (regime que precedeu a Revolução), era permitido aos plebeus com certo mérito intelectual discursar em pé de igualdade com os nobres. É importante aqui sublinhar que Rousseau conseguiu sua notoriedade política e influência intelectual graças a estas mulheres, que posteriormente tanto ele quanto a maior parte dos plebeus negaram-lhes a igualdade (Ibid., p. 13).

Foi de grande valia o trabalho realizado por mulheres que faziam parte do movimento 
feminista do Séc. XX, sobretudo nos anos 70, que consistiu na recolha e exame crítico em torno dos textos do corpus filosófico, sobretudo daqueles que eram expoentes da misoginia (aversão e ódio por mulheres) dentre eles Aristóteles, Kant, Rousseau, Hegel, etc.. Estas mulheres trouxeram à tona a maior parte das barbaridades enunciadas por estes filósofos em relação às mulheres. Foi, aliás, esta ideia que serviu de guia e base para encetar-se o árduo caminho rumo à emancipação.

É oportuno aqui salientar que

o nascimento de uma história das mulheres inscreve-se no campo mais vasto das ciências humanas, desigualmente visitadas pelo sexo. (...) Própria (...) do conjunto do mundo ocidental. Os Estados Unidos foram pioneiros, utilizando às vezes elementos elaborados pela velha Europa e por ela desprezados. A vida intelectual é feita destas idas e vindas. Destas incessantes bricolagens (PERROT, 2005, p. 15).

Neste contexto de luta pelo acesso à educação foi de grande valia o início do movimento “de mulheres mais cultas reagindo às injunções sociais que restringem o seu papel na sociedade [e aquele que em paralelo era contra] (...) as de poucas letras, acomodadas à posição "vantajosa" de inferioridade" (BERNARDES, 1989, p. 125).

No Séc. XIX com o advento das tecnologias, o crescente crescimento da riqueza como reflexo do capitalismo e da industrialização várias foram as transformações ocorridas na estrutura e vida da familiar, o que necessariamente obrigou a repensar-se a educação (instrução) e o papel das mulheres (meninas), no sentido de que desde muito cedo deveriam aprender a contribuir para o progresso social, cultural, económico, politico, cientifico etc. Numa tendência liberal este pensamento pedagógico foi acompanhado por nítidas preocupações com a educação da meninas para a vida em sociedade relacionando a educação sobretudo com o progresso social e a educação com o bem-estar.

Em termo práticos, não há dúvidas que os factos ligeiros porém violentos demonstravam que era necessário libertar-se a mulher dos condicionamentos das normas sociais e da educação moral tradicional que lhe era imposta. Todavia,

a sociedade oferecia, como o faz ainda hoje, sérias resistências à instrução da mulher, resistências essas que se avolumam à medida que se sobe na escala de escolarização. De qualquer modo, o alargamento dos horizontes culturais da mulher urbana, a limitação de natalidade [o direito ao aborto, o uso de métodos de contracepção], o recurso crescente ao processo legal da separação conjugal [são elementos essenciais que] constituem dados reveladores de que a posição social da mulher vem sofrendo uma redefinição constante pelo menos nos 
centros dinâmicos da vida social (SAFFIOTI, 1976, p. 180 Apud ROSA, 2012, p. 71).

Ora, não se deve ignorar que a vida da mulher que antes restringia-se a eterna clausura, em que a casa do pai ou do marido eram o prolongamento do convento, sofreu algumas mudanças à proporção que se intensificava o processo de urbanização, levando-a a deixar de ser uma reclusa no interior de sua própria casa. Isto contribuiu para que o modelo patriarcal de educação aos poucos perdesse dimensão rígida, permitindo, deste modo, a que a mulher pouco e pouco desenvolvesse real desembaraço em relação a certos comportamentos e/ou atitudes.

Facto é que na sociedade hodierna a veiculação da ideia da necessidade da educação e emancipação da mulher emerge justamente da tomada de consciência que educar a mulher é contribuir para a dignidade, não somente da família mas da nação e do mundo, isto é, da humanidade como um todo, e da compreensão que a grandeza de qualquer nação reside no reconhecimento que a mulher é eixo vital da sociedade.

Vale dizer, então, que a ênfase à sólida educação da mulher, sobretudo o incentivo ao estudo, e por conseguinte, a formação em qualquer área que ela desejasse, sem contudo ignorar o seu papel social de filha, irmã, prima, sobrinha, mãe, esposa é recente. De modo igual, é também recente a abertura para o mundo de trabalho e a exigência pela sua inserção em todos os sectores sociais e o merecimento de respeito, reconhecimento do seu contributo como cidadã para o progresso social, económico, político, cientifico, académico, etc.

Determinados estes aspectos, um ponto fica ainda por considerar, é o facto de na actualidade, mesmo que "nadando contra a maré", em um mar prenhe de preconceitos de toda a sorte, a mulher no geral e a filósofa em particular pouco e pouco vem priorizando, assumindo e desenvolvendo inúmeras actividades nas áreas de ensino, pesquisa e extensão, tendo como pano de fundo "diversas questões e temáticas, com distintas perspectivas teóricas e enfoques metodológicas" (ROSA, 2012, p. 85).

\section{Ausência de literatura filosófica feminina no ensino de filosofia}

Antes de mais duas questões primordiais se fazem necessárias, a saber:

O Porquê de as mulheres não aparecerem em muitas reflexões filosóficas (...) quase não há citações e estudo de ideias de mulheres em pesquisas. Raramente, elas aparecem nos livros de Filosofia. Os clássicos são estudados, como se numa história a prior as mulheres não fizessem parte da humanidade. 
De maneira fragmentada e bipolarizada, aprendo filosofia como se ela fosse anexa a mim como mulher e não parte de nossas mentes e vivências (ROSA, 2005a, pp. 1-2 Apud ROSA, 2006, p. 19).

E hoje? Qual é o papel das mulheres na Filosofia? Será que estamos cientes do confinamento, do suposto esquecimento e silenciamento que foi dado às pensadoras da história da Filosofia? O que as mulheres na Filosofia fazem hoje para que "outros" não a representem? (ROSA, 2006, p. 19).

Um ponto de suprema importância a ser tomado em linha de conta é o caso de tradicionalmente as distinções e os preconceitos relacionados aos pobres, negros, estrageiros, às mulheres, viúvas e crianças fazerem parte da História no geral e da Filosofia em particular. A prova que abona em favor disso é o facto de ao questionar-se se existem mulheres pensadoras e filósofas e, de modo igual, ao verificar os manuais é fácil concluir que "que jamais existiram", porquanto o corpus filosófico tradicional é completamente masculino.

De alguma forma, graças ao movimento e à teoria feminista inaugura-se uma nova fase na qual algumas pensadoras filósofas, anteriormente menosprezadas e seu trabalho intelectual desvalorizado, seus escritos não conservados por não serem dignos de reconhecimento e por via disso foram perdidos, pelo simples facto de serem mulheres, aos poucos são reconhecidas, como uma forma de minimizar a invisibilidade da mulher. As mulheres historiadas aparecem como pioneiras a lutar contra a invisibilidade das mulheres na História.

Na segunda metade do século XX, examinando os livros e manuais de história, perguntaram-se onde estavam as mulheres. Havia apenas uma História de generais e imperadores, com algumas poucas mulheres, Cleópatra e algumas mais, em geral mencionadas como as malvadas (PULEO, 2004, p. 14).

É bem verdade que seguindo os passos das mulheres historiadoras, as historiadoras da filosofia enveredaram no árduo trabalho de recuperação, análise minuciosa e restauração, porém ao tentar dialogar com as filósofas não puderam entrar em contacto com os textos originais e tiveram que ajustar-se com as produções que narravam o que elas realizavam e/ou expunham e assim reconstruir suas figuras. Ora,

dentro desse grande esforço de recuperação da criação cultural feminina, devemos mencionar a edição crítica de obras inacessíveis ao público por não terem voltado a ser publicadas desde sua aparição ou nunca terem sido traduzidas. Nesses casos, tende-se a sublinhar a contribuição original dessas obras esquecidas (PULEO, 2004, p. 14).

Observe-se que a partir do exame das capacidades criadoras e dos estudos das mulheres 
filósofas e que despertam atenção e interesse destacam-se as seguintes:

Rosa Luxemburgo (1871-1919) filósofa e economista marxista polaco-alemã, cujas obras de realce são Reforma ou Revolução? (1899), Greves de Massas, Partidos e Sindicatos (1906) e A Acumulação do Capital (1913). Luxemburgo reflectiu e escreveu sobre a mulher operária.

Maria Zambrano (1904-1991), filósofa espanhola, discípula de Ortega Y Gasset e Xavier Zubiri, fortemente influenciada por Heidegger, Spinoza. Dentre as suas obras destacamse $O$ Homem e o Divino e Os Sonhos e o Tempo. Zambrano reclamou a emergência de uma razão poética que opere como mediação com a terra para superar o racionalismo moderno.

Hannah Arendt (1906-1975) filósofa política alemã-Judia, uma das mais influentes do Séc. XX. Teve forte influência de Heidegger, Jaspers, Marx e Kant. As suas obras de relevo são As Origens do Totalitarismo (1951), A Condição Humana (1958), Eichman em Jerusalém, Entre o Passado e o Futuro (1961) e a Vida do Espirito (1977). Arendt substituiu a categoria de mortalidade privilegiada pelo seu mestre Heidegger pela de natalidade, a qual "implica um ponto de vista novo, que aponta para uma implícita dignificação do corpo e ao mesmo tempo permite pensar a pluralidade em termos que vão além do simples pluralismo do "vale tudo" (Ibid., p. 15).

Simone de Beauvoir (1908-1986) filósofa existencialista francesa, escritora, intelectual, activista política, teórica social e principal teórica feminista do Séc. XX. Com ela tem-se um caso no qual a filosofia determina em grande medida o surgimento de um movimento social. Suas grandes obras são O Segundo Sexo (1949), A Mulher destruída (1967), A Convidada (1943), Por uma moral da Ambiguidade (1947) Uma morte muito suave (1964), O sangue dos outros (1945) e A força da idade (1960).

Beauvoir a partir do existencialismo, constrói uma conceitualização filosófica da feminilidade para censurar a "hetero-designação", termo que se referia à peculiar condição das mulheres serem definidas e explicadas de fora e, por conseguinte, de forma limitada, designando-as como mães ou meretrizes desde tempos remotos. Afirmara que admitir e acolher a definição do ser mulher e de suas funções, ocupações e cargos de quem se autodefine como o autêntico Sujeito contrariamente do que se pensa é o corolário da carência de poder (Ibid., p. 16).

Defende a tese fundamental segundo a qual ser mulher é uma construção não biológica, tese abreviada na sua célebre frase "não se nasce mulher torna-se mulher". Esta percepção levou a compreensão que a opressão sofrida por mulheres em todas dimensões e áreas é uma 
construção social e não é algo natural e inalterável. Assevera que o matrimónio igualmente é fenómeno cultural e não uma inclinação da mulher.

\begin{abstract}
A antropologia filosófica existencialista dá a Simone de Beauvoir um marco adequado para criticar o essencialismo tradicionalista. Nesta filosofia de ruptura, o homem é concebido como o que não tem essência, mas existência, o que significa que é autoconstrução, que não é um ser predefinido, como no típico exemplo da mesa, que tem uma definição porque tem sido desenhada para uma função. Segundo o existencialismo, cada ser humano vai-se definindo através do que vai elegendo em sua vida. Com nossas grandes e pequenas decisões, em cada momento vamos decidindo quem seremos. Esse projeto - que é o ser humano - no caso das mulheres, diz Simone de Beauvoir, está truncado, porque para poder ser projeto, para ser meu próprio projeto, tenho de ter um âmbito de possibilidades de escolha. Se não me concedem mais do que uma possibilidade, não há escolha, não há liberdade. Por isso, Simone de Beauvoir rejeita em 1949 a definição de "a mulher" com um único destino, ser esposa e mãe. E reivindica a saída das mulheres do fechado âmbito doméstico para o mundo da criação cultural, da racionalidade, da política (PULEO, 2004, pp.16-17).
\end{abstract}

Simone Weil (1927-2017), política e francesa e ícone na luta contra a discriminação das mulheres. Crítica do totalitarismo que levou seu compromisso a ponto de trabalhar como operária em uma fábrica.

Judith Butler (1956-até o presente) é uma filósofa política e ética norte-americana, pósestruturalista e grande teórica da questão contemporânea do feminismo. De suas várias obras as que tem enorme repercussão são: Problema de Gênero: O feminismo e a subversão da identidade (1990), Desfazer o género (2004), Bodies That Matter: On the discursive limits of sex (1995), Vida precária (2004), Quadros de Guerra: Quando a vida é passível de luto? (2009). Butler problematiza o conceito gênero, concebendo-o como não binário, fluido e constituído por comportamentos que simplesmente compõem performance.

Tendo em conta o exposto até então, deixemos assente por ora que antes de mais, é preciso reconhecer que como pensamento que busca transcender a realidade, a filosofia tem, muitas vezes, sido capaz de gerar textos críticos, emancipatórios do ponto de vista das classes, das raças etc., e também tem produzido textos emancipatórios do ponto de vista dos sexos, mas esse conjunto de obras é, justamente, o que a história oficial não recolhe, posto que parece não nutrir qualquer tipo de interesse pelos mesmos, o que denota a ausência de um corpus filosófico não-sexista.

Embora, cada vez mais, haja clareza e quase consenso no quesito de que não há como educar sem fazer-se menção às relações de gênero no ambiente didáctico-pedagógico, isto é, na 
sala de aulas, e tampouco não há como não fazer-se referência às mulheres na História Universal e da Filosofia, ainda é facto que quer no ensino superior quanto no secundário, os currícula legitimam o preconceito e a exclusão de textos filosóficos femininos, à medida que não fazem parte dos seus programas de ensino, dos livros didácticos, das bibliotecas assim como das livrarias. Dito em outras palavras, existe um ocultamento de toda a obra filosófica feminina.

Eis, então, de uma maneira geral, que adentrando na História da Filosofia no geral e na Literatura Filosófica em particular é perceptível a lacuna em torno da vida e obra de mulheres filósofas, isto revela claramente que o espaço filosófico sempre foi dominado por homens, ou seja, é um espaço masculinizado, consequência de uma sociedade patriarcal, de visão androcêntrica que terminantemente exclui as mulheres, contribuindo sobremaneira para que seus saberes sejam desconsiderados.

Ademais, resulta manifesto o silêncio ensurdecedor em torno da divulgação, estudo e ensino de obras filosóficas escritas por mulheres. Este preconceito de gênero no mundo do saber filosófico contribui de forma ímpar e violenta para que se desconheça toda a produção intelectual de mulheres filósofas. Há um cativeiro criado a partir do preconceito, quase sempre velado, todavia real, que exclui as mulheres filósofas do universo académico, e consequentemente todo o seu legado (conhecimento filosófico), imerso na riqueza de suas ideias e reflexões, repleto de lutas e realizações interessantes e válidas. Todo esse legado é explicitamente oculto no submundo do conhecimento e enclausurado, como se de algo secreto e proibido se tratasse.

É legítimo pensar e afirmar que as obras filosóficas femininas são deliberadamente consideradas menores, insignificantes, como se somente aos homens coubesse o pódio, os melhores lugares e o mérito, e às mulheres reservado os bastidores, o esquecimento e/ou o anonimato. São poucas as mulheres que notoriamente "escaparam" do cativeiro e de forma imponente conseguiram impor-se com reconhecimento no universo filosófico masculino.

Conforme afirmou-se anteriormente, é escassa uma literatura de carácter forte que partilha os méritos das mulheres e destaca as suas capacidades no campo científico em geral e da filosofia em particular. São muito poucas as mulheres que, no interior do vasto e complexo corpus filosófico escreveram sobre sua história de vida, sobre seu pensamento e sobre a história do pensamento de mulheres e simultaneamente assumiram o registo destas três perspectivas em suas obras, salvo algumas excepções acima já referenciadas. É influenciado por este verdade que 
Telles (1997) afirma que, no século XIX, para as mulheres que pensaram em ser algo mais do que "bonecas" ou personagens literárias, os textos dos escritores colocaram problemas tanto literários quanto filosóficos, metafísicos e psicológicos. Como a cultura e os textos subordinam e aprisionam as mulheres, muitas precisaram escapar dos textos masculinos que as definiam como ninharia, nulidade ou vacuidade, como desvaneio, e tiveram de adquirir alguma autonomia para propor alternativas a autoridades que as aprisionavam (ROSA, 2012, p. 81).

A constatação acima reforça claramente o facto de que embora a comunidade cientifica e/ou o paradigma científico advogue que para a validação e o reconhecimento epistemológico de toda a produção intelectual deve-se estar desobrigado de qualquer juízo subjectivo de valores prevalecendo somente a pertinência e a validade do saber manifesto, o preconceito em relação a mulher filósofa aliado ao critério sexo, e que redunda na exclusão e no anonimato de toda a sua produção intelectual, constituem sinais claros da inexistência do juízo subjectivo de valores, de respeito pelos princípios éticos que devem guiar e orientar a comunidade cientifica.

Ainda assim, de modo geral, a maior parte das mulheres carece de igual liberdade perante os homens, facto que não raras vezes contribui para que elas precisem escrever anonimamente ou mesmo a partir de uso de pseudónimos, e apesar disso acabam não vendo suas obras inseridas no horizonte científico. É raro encontrar mulheres filósofas sendo lembradas como grandes escritoras e, por via disso, tidas como figuras de referência na filosofia e no seu ensino.

É no interior do contexto até então exposto que Bourdieu sabiamente questiona o seguinte:

Como reconstruir os olhos das mulheres, como tratar enquanto sujeitos de percepção - e por si próprias, durante todo tempo em que apliquem a si mesmas as categorias de percepção dominantes, ou seja, masculinas, e se vejam com um olhar masculino? (BOURDIEU, 2000, p. 59).

Ora, é, pois, claro que em virtude do tipo de formação académica, maioritariamente machista, a mulher filósofa apresenta-se formatada a pensar a partir de uma mentalidade masculina, tanto é que mesmos em suas produções e/ou escritos (artigos, monografia, dissertação, tese, livros etc.) tem dificuldades de usar obras femininas ou até mesmo de aventura-se sobre uma temática feminina, de citar mulheres filósofas ou não, isto é, de trazer argumento cuja referência seja feminina.

No entanto, o desafio de inserir a vida e obra (pensamento e ideias) das mulheres filósofas na História da Filosofia e por conseguinte no Ensino da Filosofia "supõe que elas 
sejam levadas a sério, que se dê a relação entre os sexos um peso, ainda que relativo, nos acontecimentos ou na evolução das sociedades" (PERROT, 2005, p. 14). De modo igual, é imperioso que se evite situar as mulheres naturalmente como vítimas ou heroínas mas seguirse um propósito cujo trajectória perentoriamente estabelece-se e inscreve-se em função do processo de produção do seu conhecimento em determinada área específica do saber a partir de suas lucubrações, inquietações, experiências de vida e jamais a partir do sexo.

Assim, ao partir do pressuposto de que a filosofia é um pensamento que influencia na percepção e reorganização do real, nada mais razoável que a efectivação da inserção da literatura feminina no interior da História da Filosofia e no Ensino da Filosofia, porquanto essa atitude

pode levar-nos a alguma coisa de maior extensão na história da humanidade. Pode ajudar-nos a ver como a sociedade funciona, como o poder e os papéis são atribuídos, como operam os mecanismos de controle social e quais as experiências individuais comuns e quais as diferenças, baseadas em sexo, raça e classe. Em potencial, (...) [o reconhecimento e a inserção do legado feminino na história da filosofia] na verdade representa o oposto do interesse estreito e sectário que lhe foi atribuído por alguns críticos. Concentra-se na "outra metade" da humanidade, fornece uma oportunidade inestimável para escapar do quadro limitado da história tradicional, e ajudar-nos-á a alcançar uma visão mais abrangente do passado (HAHNER, 1981, p. 23).

A terminar esta secção faço minhas as palavas de Puleo

se lermos o cartesiano feminista Poulain de La Barre, filósofo muito conhecido no final do século XVII que hoje não é lembrado por ninguém exceto quem trabalha em temas de gênero -, e se sabemos que seu livro sobre a igualdade entre os sexos era muito famoso naquela época, que todas as mulheres ilustradas de seu tempo o liam e alguns homens concordavam com ele, e se além disso sabemos que Rousseau tinha um exemplar em sua biblioteca, então entendemos melhor o que escreve este filósofo em Emílio. Está respondendo a Poulain de La Barre e a seus muitos seguidores. Isto é, se entende melhor os autores reconhecidos pela tradição filosófica se conhecemos a outra voz, a voz que foi silenciada (PULEO, 2004, p. 8).

\section{Desafios do ensino da filosofia livre do preconceito e da exclusão da mulher}

Todo o processo de ensino é plural e complexo, e o ensino de filosofia não é execepção. A peculiaridade da filosofia e da prática educativa filosófica de per si pressupõem e despertam uma série de temáticas, teses, argumentos e questões de ordem teórica e prática que demandam uma atenção diferenciada em relação as outras disciplinas, porquanto a prática lectiva filosófica 
é um exercício abstracto que transforma a sala de aula em autêntico laboratório conceptual e gnosiológico por excelência.

Ora, dado que a filosofia é parte integrante da vida e do quotidiano humanos e, consequentemente, um dos grandes espaços privilegiados para a reflexão de aspectos relacionadas com tudo o que diz respeito ao homem e à mulher, às suas vidas, direitos e deveres, ao universo, em suma, à totalidade, é de extrema importância que na elaboração dos curricula de filosofia se proponha uma filosofia contemporânea que se desdobra em uma filosofia que não seja apenas sistemática ou simples estudo das ideias dos filósofos e das filósofas, mas sobretudo uma filosofia social, política, ética e humana actuante, pois "à medida que não apresenta um saber positivo, prático, operacional, a filosofia fica sob suspeita, marginalizada" (COÊLHO, 2001, p. 34).

Com efeito, esta filosofia deve centrar-se numa epistemologia edificante, que considera como algumas das suas grandes responsabilidades e compromisso, o não-sexismo, a descodificação e a modificação do essencial da actualidade do mundo, o investimento, não apenas na sua interpretação mas na abertura de amplos espaços para transformação e acção social concreta na e da sociedade, isto é, trata-se de uma filosofia adequada ao mundo social, que simultaneamente, na explicitação de seu sentido e contingência, consequentemente actua como factor e vector de progresso, humanização e luta contra todo tipo de preconceito e exclusão.

Efectivamente, o esforço de explicitação do aspecto pragmático da filosofia

está vinculado a uma compreensão crítica da própria filosofia, enquanto filosofia da práxis, que de forma dialéctica, superando toda forma de idealismo subjectivista ou objectivista, afirma-se, enquanto constituidora da racionalidade emancipatória, libertadora, que assume a crise da razão como problema e desafio não apenas especulativo, mas também político, gnosiológico e cultural (HORN, 2004, p. 276).

Marx constitui um dos expoentes na preocupação por uma filosofia da práxis, ao advogar que a filosofia deve estar comprometida com a superação da realidade opressora e excludente e ao fornecer uma visão da transformação social e de acção humana a partir ou/e por meio da filosofia. Daí que, determinado a levar adiante essa transformação do mundo pela filosofia, distanciou-se da função contemplativa, apelando a filosofia a pautar por uma via interpretativa e transformadora do mundo, isto é, uma filosofia que passa da teoria à acção (prática). Sugeriu uma tarefa mais interventiva, ao afirmar que a filosofia precisa incidir sobre 
a realidade, afastar-se da especulação abstracta e entrar em contacto com a realidade e ao insistir que para transformar o mundo é necessário vincular o pensamento à prática revolucionária.

Desta forma, fica cada vez mais claro que, na discussão sobre a problemática da prática educativa filosófica, vale a pena considerar e englobar a função pragmática da filosofia. Esta proposta supõe um trabalho árduo, que consiste em rever e revelar o lado prático da filosofia, sobretudo com a adequação desta ao meio e à evolução social, visto que, a filosofia e o filosofar revitalizam-se mediante o processo de construção, produção e transformação e não apenas de contemplação. Por esta razão, a filosofia em contacto com a realidade, deve trabalhar por um aperfeiçoamento constante da vida pessoal e em sociedade, a fim de explicitar as suas virtualidades e potencialidades.

Segundo Chauí, os amantes e as amantes da filosofia não devem ficar perturbados, aborrecidos e impacientes quando lhes é dirigido a questão para que filosofia?, pois, ela tem razão de ser, porque a sociedade está acostumada a considerar que algo só tem razão de ser, ou seja, de existir, se tiver alguma finalidade prática, e se for de utilidade rápida. Para a questão acima, Chauí em jeito de resposta apresenta o lado pragmático da filosofia ao frisar que

o principal para a Filosofia não seriam os conhecimentos (que ficam por conta da ciência), nem as aplicações de teorias (que ficam por conta da tecnologia), mas o ensinamento moral ou ético. A Filosofia seria a arte do bem viver. Estudando as paixões e os vícios humanos, a liberdade e a vontade, analisando a capacidade de nossa razão para impor limites aos nossos desejos e paixões, ensinando-nos a viver de modo honesto e justo na companhia dos outros seres humanos, a Filosofia teria como finalidade ensinar-nos a virtude, que é o princípio do bem-viver (CHAUÍ, 2000, p. 11).

É mister conceber a atitude filosófica como o grande legado da própria filosofia. Ela enquanto acto de indagar é constituída por duas faces: a negativa, que consiste em dizer não ao senso comum, aos preconceitos (ídolos), a exclusão e a positiva, que é a interrogação incessante sobre o que são as coisas, as ideias, os factos, as situações, os valores, os seres humanos, portanto homens e mulheres, o por quê de tudo o que é e por que não é de outra forma. A face negativa e positiva da atitude filosófica constituem a atitude crítica e o pensamento crítico, uma vez que,

o exercício da filosofia nos educa para a dúvida, a crítica, a contestação, o pensamento radical e rigoroso das teorias e das práticas, a superação da visão ingénua do real como pronto e acabado, a busca do sentido e da génese, dos pressupostos e das implicações do existente (COÊLHO, 2001, p. 45). 
Assim sendo, a filosofia deve apresentar-se como uma contribuição no esforço humano de aclarar o sentido da vida; um esforço infindável, posto que, o sentido da existência, por ser social e historicamente determinado, é constantemente alterado, isto é, altera-se a cada momento. Concomitantemente, deve-se conceber o papel do filósofo e da filósofa, como o de um indivíduo intimamente engajado na crítica social e não como participando em exercício abstracto de contemplação que permanece dissociado da moralidade prática. O papel dos filósofos e das filósofas deve ater-se à mutabilidade permanente do mundo e não somente na busca da verdade, guiados por um olhar crítico dirigido às necessidades sugeridas pela experiência colectiva.

Logo, deve-se deixar para trás a velha atitude do filósofo, fundador do último sistema e adoptar-se uma atitude muito mais razoável e modesta, que busca auxiliar a estabelecer o mais compreensível método de julgar, com integridade e coerência, os valores reais da vida actual, para o efeito de dirigi-la para uma vida cada vez melhor e mais rica, livre de pré-julgamentos e preconceitos de toda a ordem. Deste modo, a filosofia tornar-se-á um processo em marcha, transformando-se, modificando-se, reconstruindo-se à medida que os homens e as mulheres operarem em suas pesquisas, transformações, modificações e reconstruções, até que esta se mostre realmente, como o queriam os antigos, a mestra da vida.

É imperioso identificar e questionar sobre que eixos estruturais, a nível de políticas educacionais contemporâneas, a filosofia deve, urgentemente, erguer-se e ser ensinada, para tornar-se num instrumento e dispositivo emancipatório, criador e incentivador de uma cultura científica humanizadora, preocupada pela partilha do conhecimento/saber, igualdade e diálogo, acolhimento e solidariedade, aceitação do outro e tolerância, rumo a um saber ser e estar, capaz de ajudar a promover a concretização efectiva de uma sociedade mais justa, hoje fortemente ameaçada.

É importar frisar que, a prática lectiva da filosofia, por um lado, deve "afirmar sua dimensão pedagógica, ética e política, tornando-se educadora de homens e mulheres, guardiã da pólis, da existência social" (COÊLHO, 2001, p. 51). Por outro lado, deve asseverar e reafirmar a validade e a universalização da filosofia livre do sexismo, reavivar a sua pragmaticidade básica, problematizar a linha comum que diferentes percursos filosóficos têm compartilhado no momento de pensar o sentido educativo da filosofia, com o intuito de construir uma filosofia mais aberta e humilde, capaz de derrotar o estandarte da omnipotência e de detentora da verdade última e que, simultaneamente, se torne em uma orientação segura para e na construção de um mundo globalizado, multicultural, democrático, livre, erguido sobre 
as base da dialogicidade, respeito pela diferença, conscientização, criticidade e sobre a fé nos homens e nas mulheres.

Por sua vez, é urgente evidenciar a filosofia não como uma ciência somente feita por homens e para homens, uma ciência que se basta a si mesma e se satisfaz com a teoria ou com "o mundo das idéias", mas como um saber essencialmente prático, ligado a todo o leque de questões que dizem respeito a vida do homem e da mulher (sociais, económicas, políticas, culturais, éticas, etc.) e não apenas uma actividade académica, técnica ou de saber reservado unicamente ao sexo masculino.

Desta feita, ao despertar e direccionar o homem e a mulher para o mundo da autonomia, liberdade, igualdade, justiça, democracia, solidariedade, etc., a filosofia deve ser apresentada como consequência das considerações a respeito do homem e da mulher e da realidade na qual ela se encontra inserida e se desenvolve, visto que, ela não parte do nada ou seja do vazio, mas das necessidades imediatas e mediatas do homem, da sociedade e do meio físico, bem como das proposições transcendentais resultantes do trato próprio ser humano (homem e mulher) consigo mesmo, a sociedade, o meio físico e o transcendental.

Ademais,

a filosofia não é alienação, não se constitui à revelia ou à margem do mundo, da sociedade, da existência humana, mas significa compromisso com a superação do mundo, da sociedade, da educação que temos, no sentido de se chegar à perfeição, de se humanizar todos os homens e mulheres, todas as instituições, toda a sociedade" (COÊLHO, 2001, p. 51).

Sem dúvida, a filosofia por meio da educação e do seu ensino deve tornar-se o espaço, por excelência, do acolhimento das boas ideias, independentemente do gênero, lugar ou da cultura da qual provenham, com o objectivo de lidar de forma mais eficaz e próspera com o ambiente, pois ela possui uma missão: a de colocar em acção o holismo, a fim de que os seres humanos possam solucionar problemas por meio de todo o espectro de suas actividades.

Portanto, frente aos múltiplos desafios da contemporaneidade, os dois rostos fundamentais da filosofia - filosofia $=$ philosophia (aspecto teórico, informativo e histórico) e o filosofar = Philosophein (aspecto prático, formativo e emancipatório), devem emergir, mais uma vez, como uma oportunidade e possibilidade no processo de formação humanista para a autonomia, formação de pessoas inteligentes, felizes e ajuizadas, mais livres de espírito (Montaigne), formação da cidadania tolerante, responsável e pluralista, formação de uma consciência ou capacidade crítica, em todas as suas formas e vertentes; crítica enquanto 
desenvolvimento de certas habilidades de raciocínio ou pensamento (Analistas), crítica enquanto um julgar com critério - Dewey, e um apreciar com cuidado - Lipman (Pragmatismo), crítica enquanto oposição à naturalização das ideias, saberes e valores dominantes (Escola de Frankfurt - Horkheimer), crítica enquanto transformação do mundo (Marx), crítica entendida como um pôr em questão todas as evidências (Pós-estruturalismo - Foucault).

Daqui, resulta ser necessário que a filosofia e a sua prática educativa (o seu ensino) devem assumir uma relevância significativa, funcionando como uma ferramenta básica capaz de fazer surgir seres humanos (homens e mulheres) culturalmente maduros, íntegros, e conscientes de sua responsabilidade sociopolítica, manifesta na participação cidadã na vida colectiva.

\section{Conclusão}

A prática do ensino e aprendizagem da filosofia demonstram que é possível educar filosofando ou filosofar educando, pois o mundo actual exige o filosofar de quem nele vive e convive, quem nele há-de viver e conviver e, neste contexto, formar gerações não filosofantes seria hipotecar essas gerações a uma eterna alienação. Por isso, num mundo em constante e acelerada transformação é uma urgência e exigência ensinar a filosofia e o filosofar dentro de um corpus filosófico que reconhece, valoriza e inclui as mulheres e o seu pensamento na sua história, literatura e ensino.

No entanto, a filosofia, a partir do seu carácter imanente, atento ao quotidiano e ao particular, do seu carácter transcendente, sempre em busca do uno e do universal, do seu carácter eminentemente prático e social, aparece como um factor importante, senão capital, e contribui de forma ímpar na formação e no desenvolvimento do ser humano, seja como fonte de crescimento, de conhecimento, de emancipação e de progresso. Contribui e influencia na edificação de uma vida melhor, digna, feliz e na consolidação de uma sociedade mais justa, democrática, assim como potencia o homem e a mulher a participarem na sociedade como indivíduos livres, com direitos e deveres iguais, conscientes, críticos e activos, em condições de resolver sabiamente os problemas fundamentais da realização do seu Ser não na situação de concorrência mas sim de cooperação e parceria.

Ora, o reconhecimento e a valorização das produções intelectuais, ideias, lutas e experiências das mulheres, e por conseguinte a sua inserção no corpus filosófico, (História da Filosofia, Literatura Filosófica, Ensino da Filosofia, Pesquisas Filosóficas, etc.) será não tão- 
somente um grande ganho no campo científico mas também e sobretudo na história da própria filosofia e humanidade, porquanto essa atitude conduzirá a uma compreensão mais clara da nossa história, do nosso presente e quiçá a um prespectivar do futuro possivelmente mais generoso.

Por conseguinte, do que foi dito ao longo de toda a exposição, segue-se, necessariamente, considerar neste contexto o facto de que dado que só se entende verdadeiramente o nosso presente se conhecemos a nossa história, é de certa forma desejável conhecer-se o que se disse sobre as mulheres e o feminino, e dessa forma entenderemos também seu oposto, os homens e o masculino. Outrossim permitirá compreender melhor a história da filosofia e a tradição heurística e hegemônica, o corpus da "história oficial" da Filosofia.

Em suma, convém ressaltar que, o ensino e aprendizagem da filosofia, de per si não garantem pessoas melhores, mas propõem perspectivas válidas que ajudam a pensar e a decidir de maneira mais clara possível e ambos (ensino e aprendizagem) se tornam significativos quando justamente reconhecem a necessidade de pensar e decidir claramente em um contexto maior de desenvolvimento individual e social, isento de todo o tipo de preconceito e exclusão.

\section{Bibliografia}

CHAUÍ, Marilene. Cultura e democracia: o discurso competente e outras falas. $5^{\mathrm{a}}$ Ed., Ed. Cortez, São Paulo, 1990.

COÊLHO, Ildeu M. Filosofia e Educação, In PEIXOTO, Adão (Org.) Filosofia, Educação e Cidadania, Campinas: Editora Alínea, 2002, p 19-70.

BEAUVOIR, Simone de. O segundo Sexo: a experiência vivida. Vol.I, Rio de Janeiro, Editora Nova Fronteira, 2000.

BERNARDES, Maria Thereza Caiuby Crescenti. Mulheres de Ontem? São Paulo, Editora, T. A. Queiroz, 1989.

BOURDIEU, Pierre. Escritos de educação. Petrópolis, Editora Vozes, 2000.

HAHNER, June E. A mulher Brasileira e suas lutas sociais e políticas: 1850-1937. São Paulo, Editora Brasiliense, 1981

HORN, Geraldo Balduíno. Filosofia, Ensino e Emancipação, In: CANDIDO, Celso, CARBONARA, Vanderlei, (Org.) Colecção Filosofia e Ensino: Um Dialogo Transdisciplinar, Editora Unijuí, Numero 5, Rio Grande do Sul, 2004, p. 269-281

MENEZES, Magali Mendes de. Da academia da razão à academia do corpo. In As Mulheres e a Filosofia. TIBURI, Márcia; Menezes, Magali de; EGGERT, Elda (org.) Editora Unisinos: 
São Leopoldo, 2002. 172p

PAZ, Octavio. O Labirinto da Solidão e Post. Scriptum. Rio de Janeiro, Editora Paz e Terra, 1984.

PERROT, Michelle. Sair. In: PERROT, Michelle; DUBY, Georges (Dir.) História das mulheres no ocidente: o século XIX. Porto, Editora Afrontamento, 1991. V4, p 503-540.

PRIORI, Mary del . Ao Sul do Corpo-Condição feminina, maternidade e mentalidades no Brasil Colônia. Rio de Janeiro, Editora José Olympio, 1995.

PULEO, H. Alicia. Filosofia e Gênero: da memória do passado ao projecto do futuro. Caderno $\mathrm{n}^{\circ} 8$ da Coord. Espec. da Mulher: Políticas Públicas e Igualdade do Gênero, Prefeitura de São Paulo, 2004.

ROSA, Graziela Rinaldi da. As Relações de Género na Filosofia: Vivências e Narrativas De Professoras De Filosofia. São Leopoldo, 2006 (Dissertação do Mestrado, Universidade do Vale do Rio dos Sinos, Programa de Pós-Graduação em Educação, São Leopoldo, RA, 2006.).

ROSA, Graziela Rinaldi da. Transgressão e moralidade na formação de uma "matrona esclarecida": contradições na Filosofia de Educação nisiana. São Leopoldo, 2012 (Tese de doutorado, Universidade do Vale do Rio dos Sinos, Programa de Pós-Graduação em Educação, São Leopoldo, RA, 2012.). 